NBER WORKING PAPER SERIES

\title{
HETEROGENEOUS WEALTH DYNAMICS: \\ ON THE ROLES OF RISK AND ABILITY
}

\author{
Paulo Santos \\ Christopher B. Barrett \\ Working Paper 22626 \\ http://www.nber.org/papers/w22626
}

\author{
NATIONAL BUREAU OF ECONOMIC RESEARCH \\ 1050 Massachusetts Avenue \\ Cambridge, MA 02138 \\ September 2016
}

Fieldwork for this paper was conducted under the Pastoral Risk Management (PARIMA) project of the Global Livestock Collaborative Research Support Program (GL CRSP), funded by the Office of Agriculture and Food Security, Global Bureau, USAID, under grant number DAN-1328-G-00-0046-00, and analysis was underwritten by the USAID SAGA cooperative agreement, grant number HFM-A-00-01-00132-00. Financial support was also provided by the Social Science Research Council's Program in Applied Economics on Risk and Development (through a grant from the John D. and Catherine T. MacArthur Foundation), The Pew Charitable Trusts (through the Christian Scholars Program of the University of Notre Dame), the Fundação para a Ciência e Tecnologia (Portugal), and the Graduate School of Cornell University. Thanks are due to ILRI - Ethiopia for their hospitality and support and to Action for Development (Yabello) for logistical support. A previous version of some of the results presented here circulated under the title "Safety nets or social insurance in the presence of poverty traps? Evidence from southern Ethiopia". We thank Ed Barbier, Michael Carter, Stefan Dercon, Andrew Foster, Vivian Hoffman, Bob Myers, Dhushyanth Raju, Wally Thurman, Stephen Younger and participants at multiple conferences and seminars for comments that greatly improved that paper. We thank Getachew Gebru and our field assistants, Ahmed Ibrahim and Mohammed Ibrahim, for their invaluable assistance in data collection. The views expressed here are those of the authors and do not represent any agency. Any remaining errors are our own. The views expressed herein are those of the authors and do not necessarily reflect the views of the National Bureau of Economic Research.

NBER working papers are circulated for discussion and comment purposes. They have not been peer-reviewed or been subject to the review by the NBER Board of Directors that accompanies official NBER publications.

(C) 2016 by Paulo Santos and Christopher B. Barrett. All rights reserved. Short sections of text, not to exceed two paragraphs, may be quoted without explicit permission provided that full credit, including $\odot$ notice, is given to the source. 
Heterogeneous Wealth Dynamics: On the Roles of Risk and Ability

Paulo Santos and Christopher B. Barrett

NBER Working Paper No. 22626

September 2016

JEL No. O1,O12,Q12

\section{ABSTRACT}

This paper studies the causal mechanisms behind persistent poverty. Using original data on Boran pastoralists of southern Ethiopia, we find that heterogeneous and nonlinear wealth dynamics arise purely in adverse states of nature. In favorable states, expected herd grow is quasi-linear and universal. We further show that those with lower herding ability, as reflected in past herd growth data, converge to a unique equilibrium at a small herd size while those with higher ability exhibit multiple stable dynamic wealth equilibria.

\section{Paulo Santos}

Department of Economics

Monash University

Building 11 E Clayton

Paulo.Santos@monash.edu

Christopher B. Barrett

Cornell University

cbb2@cornell.edu 


\begin{abstract}
This paper studies the causal mechanisms behind persistent poverty. Using original data on Boran pastoralists of southern Ethiopia, we find that heterogeneous and nonlinear wealth dynamics arise purely in adverse states of nature. In favorable states, expected herd grow is quasi-linear and universal. We further show that those with lower herding ability, as reflected in past herd growth data, converge to a unique equilibrium at a small herd size while those with higher ability exhibit multiple stable dynamic wealth equilibria.
\end{abstract}

\title{
1 Introduction
}

Contemporary policy debates are rife with discussion of "poverty traps". 1 Several theoretical models combine some non-convex technology with some market failure to explain why 'the poor stay poor and the rich stay rich". But do poverty traps exist in the data? One prominent strand of the empirical literature that addresses this question has mainly focused on searching for a threshold effect associated with multiple dynamic equilibria in the growth process, with one such equilibrium below a poverty line. The results of such studies remain quite mixed, with some studies finding support for the hypothesis while others, find no evidence of such a threshold (for reviews see Barrett and Carter (2013), Kraay and McKenzie (2014), Barrett, Garg, and McBride (forthcoming)). ${ }^{2}$

Nonlinear dynamics may arise for any of several reasons, including shocks that perturb key state variables (Carter and Barrett, 2006). It has been long understood that if there exist wealth thresholds at which growth dynamics bifurcate, then positive draws from the distribution of states of nature can move some fortunate individuals above the threshold, while negative shocks may generate persistent poverty if they exogenously drive others below the

\footnotetext{
${ }^{1}$ See, for example, Sachs (2005) or United Nations Millenium Project (2005).

${ }^{2}$ See also Azariadis and Stachurski (2005) or Bowles, Durlauf, and Hoff (2006) for good reviews of the theoretical and early empirical literature on poverty traps.
} 
threshold. In this paper, using original data from a poor population of livestock herders (i.e., pastoralists) in southern Ethiopia for whom livestock, especially cattle, are the main (often, the only) non-human asset they own, we find that nonlinear wealth dynamics arise only under adverse weather conditions. The powerful implication is that risk exposure is itself central to the very existence of multiple wealth equilibria in this system.

Why might that be? One possibility is heterogeneity among herders in their ability to manage risk. There may exist "convergence clubs" based on intrinsic, unobservable characteristics such as skills or ability. ${ }^{3}$ Perhaps the talented can more easily escape poverty or perhaps the disabled are especially unlikely to do so, regardless of initial wealth. The role unobservable ability or skill plays in determining earnings has long been recognized in studies of the private returns to education (Card, 1995) or in the analysis of who becomes an entrepreneur (Evans and Jovanovic, 1989). Of particular relevance to this paper, Schultz (1975) emphasizes the central importance of individual ability to reallocate scarce resources optimally and quickly in response to shocks, what he terms 'the ability to deal with disequilibria'. We know of no previous study that explicitly considers the role of individual heterogeneity in shaping wealth dynamics at micro-level, especially one rooted in the Schultzian ability to manage economic disequilibria such as arise from weather shocks.

These two explanations for heterogeneous and nonlinear wealth dynamics, risk and ability, may be closely related. It may be that risk can be a source of persistent poverty due to the differential ability to cope ex post with shocks (Dercon, 1998), or to manage shocks ex ante due to risk preferences and access to alternative risk management tools (Rosenzweig and Binswanger, 1993, Carter, 1997). Thus, variation in returns to assets and their relation with ability, across states of nature, may be central to understanding how both individual-level characteristics and initial conditions affect wealth dynamics.

\footnotetext{
${ }^{3}$ Baumol (1986), DeLong (1988) and Canova (2004) define and discuss the estimation of convergence clubs in macroeconomic growth data.
} 
We can represent wealth dynamics rather generally as follows:

$$
y_{i s t}= \begin{cases}g_{s B}^{c}\left(y_{i t-1} \mid \theta_{i}\right)+\varepsilon_{i s t} & \text { if } y_{i t-1}<\gamma^{c} \\ g_{s A}^{c}\left(y_{i t-1} \mid \theta_{i}\right)+\varepsilon_{i s t} & \text { if } y_{i t-1} \geq \gamma^{c}\end{cases}
$$

where $y_{i s t}$ is a measure of wealth of individual $i$, who belongs to cohort $c$, in state $s$ in period $t$, and growth dynamics may differ above and below any cohort-specific threshold, $\gamma^{c}>0$. If there exists no threshold, then unique, smooth path dynamics exist for each cohort. If a threshold exists, path dynamics may bifurcate, as reflected in different parameters describing the growth function above (A) and below (B) the threshold. The dynamics themselves are conditioned by both the individual's unobserved ability, $\theta_{i}$, and its initial conditions, $y_{i t-1}$, assuming a first-order Markov process. This general formulation nests within it the familiar neoclassical growth function with no variation across individuals or cohorts and no threshold. It also nests within it conditional convergence, wherein $g_{s B}^{c}(\cdot)=g_{s A}^{c}(\cdot)$, or a straight multiple equilibrium system without differentiation by ability or cohort. We use this general formulation both to recognize that one rarely knows ex ante which specific form wealth dynamics take and that multiple mechanisms could be at play simultaneously.

This matters because the policy implications of the convergence club and threshold-based multiple equilibria mechanisms differ markedly. If poverty is a unique dynamic equilibrium because of immutable individual characteristics, ongoing social transfers may be the only available remedy for an unacceptably low standard of living. But if poverty results from initial asset holdings insufficient to clear a critical minimum endowment threshold and thereby follow a positive accumulation path, then asset transfers, changes to the productivity of existing assets, or financial intermediation to enable investment can yield increases in wealth that move beneficiaries towards a higher-level equilibrium, thereby reducing, or even eliminating, the need for 
ongoing transfers (Carter, 1998). If both processes are at play within a population, then effective targeting of appropriate interventions depends on identifying the relevant subpopulation to which a given poor household belongs.

Sorting out the mechanisms that underpin persistent poverty is therefore enormously important in practical terms, but also quite difficult methodologically. Barrett and Carter (2013) and Barrett, Garg, and McBride (forthcoming) identify a range of confounding factors that challenge identification of poverty trap mechanisms, several of which our unusual data let us overcome. We study a relatively simple system in which a single, scalar-valued variable (livestock holdings) serves as an excellent proxy for overall wealth, we have household-level panel data that permit us to establish initial conditions and to estimate herd management ability, and we have data on household's expected herd growth conditional on particular states of nature. To the best of our knowledge, these attributes are unique to these data and permit a deeper exploration of the genesis of multiple dynamic wealth equilibria than has been feasible previously.

We make no claim to external validity of our empirical findings beyond the particular setting we study. Rather, the value of this exercise lies in unpacking the structure behind a poverty trap mechanism already established among this population in other data. Among Boran pastoralists, a poor population in southern Ethiopia, livestock herd evolution is characterized by boom-and-bust cycles determined by drought and biological reproduction. Using 17-year herd history data collected by Desta (1999), Lybbert et al. (2004) find herd dynamics that follow an S-shaped curve with two stable dynamic equilibria (at roughly 1 and 35-40 cattle), separated by an unstable dynamic equilibrium, a threshold at 15-20 cattle. Barrett et al. (2006) find similar herd patterns in herd dynamics data from similar communities in northern Kenya. The authors conjecture that this threshold results from a minimum critical herd size necessary to undertake migratory herding to 
deal with spatiotemporal variability in forage and water availability. Those with smaller herds are forced to stay near their base camps, where pasture conditions soon get degraded, leading to a collapse of herd size towards the low-level stable equilibrium, while those with bigger herds can migrate in search of adequate water and pasture, enabling them to sustain far larger herds. Toth (2015) corroborates that herd mobility is sharply increasing in herd size in the neighborhood of the herd size thresholds Lybbert et al. (2004) identify. Santos and Barrett (2011) likewise find informal credit arrangements behave as one would predict in the presence of such thresholds. These findings from east African pastoralist are among the strongest empirical evidence Kraay and McKenzie (2014) find in support of the multiple equilibrium poverty traps hypothesis.

For this paper, we collected new data among the same population (but not the same households) as those studied by Desta (1999) so as to explore the role of shocks and ability in shaping wealth dynamics. The next section briefly explains the data. In section 3, we use data on pastoralists' expectations of herd size one year ahead, given different values of initial herd size. We disaggregate these dynamics as a function of respondents' expected rainfall states and find a non-linear relation between initial and future wealth that arises exclusively in adverse states of nature. Under favorable rainfall regimes, respondents' subjective perceptions suggest a smooth asset growth process. We use these data to simulate long-run equilibria that we show correspond closely with those identified by Lybbert et al. (2004) in the historical data. We also note considerably larger variation among households in expected herd dynamics under adverse states of nature, which raises the possibility of household or individual characteristics that might generate such cross-sectional variation.

Section 4 then explores that possibility using stochastic growth frontier methods to obtain household-specific estimates of technical efficiency, which we use as proxy for herding ability. We use these estimates to explore the 
hypothesis that herder's ability conditions wealth dynamics. This appears true in the data. Low ability herders (which we define as those in the bottom quartile of the ability distribution) are expected to slide into poverty regardless of initial wealth; we observe multiple dynamic herd size equilibria only for herders of higher ability. In Section 5 we apply this approach to the analysis of the expected evolution of the wealth of a sample of herders in this region. We find evidence that ability makes a significant difference in terms of expected wealth and inequality in this system. Section 6 concludes, stressing the policy implications of these findings with respect to complex wealth dynamics and the centrality of shocks and individual ability to understanding the existence of multiple equilibria in this system.

\section{Data}

We use data from a household survey fielded among a random sample of 120 Boran pastoralist households, in the same four communities of southern Ethiopia as those studied by Lybbert et al. (2004), although among different households. These data were collected by the Pastoral Risk Management (PARIMA) project every three months, March 2000-June 2002, and then annually each September-October starting in 2003. The focus of the project, and consequently, of the data collected, was on understanding the importance of shocks as a source of poverty persistence in this context, and the data include rich detail on household composition, migration histories, changes in herds, shocks, informal transfers of assets, etc. Barrett et al. (2004) describe the location, survey methods and available variables. In section 4 we use these data, briefly summarized in Table 1, to estimate herd growth frontiers, from which we can estimate household-specific ability.

The respondents are, as a rule, male, experienced in herd management and, to a large extent, have not migrated from where they were born. Conditional on owning livestock, cattle represents approximately $85 \%$ of their 
Table 1: PARIMA data: definition and descriptive statistics

\begin{tabular}{llcc}
\hline \hline Variable & Definition & Mean & Std. Err. \\
\hline cattle & as \% of TLU & 0.85 & 0.22 \\
herd size at t & herd size at t & 9.18 & 12.87 \\
herd size at t- 1 & herd size at t-1 & 8.12 & 11.35 \\
no cattle at -1 & $=1$ if owns no cattle at t- 1,0 otherwise & 0.19 & 0.39 \\
herd below threshold at $\mathrm{t}-1$ & $=1$ if $0<$ herd size at t- $1<15,0$ otherwise & 0.68 & 0.47 \\
herd above threshold at $\mathrm{t}-1$ & $=1$ if herd size at t-1 $>15$ & 0.14 & 0.35 \\
labor & family size at t & 5.50 & 3.36 \\
land & land cropped in June 2000 & 1.12 & 2.25 \\
sex & $=1$ if male & 0.64 & 0.48 \\
experience & years since start of herd management & 20.26 & 14.07 \\
migrant & $=1$ if migrated to where currently lives & 0.21 & 0.41 \\
Dida Hara & $=1$ if lives in Dida Hara & 0.25 & 0.43 \\
Dillo & $=1$ if lives in Dillo & 0.25 & 0.43 \\
Qorate & $=1$ if lives in Qorate & 0.25 & 0.43 \\
Wachille & $=1$ if lives in Wachille & 0.25 & 0.43 \\
\hline
\end{tabular}

total TLU, and only 7 households own more livestock in species other than cattle. An important fraction (close to 1 in 5 households) own no cattle. These households are sedentarized and depend heavily on relief food distribution in towns. They own few, if any, other non-human assets so even for these stockless households livestock holdings serve as a reasonable proxy for wealth.McPeak, Little, and Doss (2011) An even more important fraction (slightly above 2 in 3 households) own herds that are smaller than 15 cattle, the accumulation threshold identified in Lybbert et al. (2004). During the period for which we have data, the average herd did grow, from an average herd size of 8.1 cattle in 2000 to 9.2 cattle in 2003 (the equivalent of a growth rate of $4.3 \%$ per year). However, this average masks important heterogeneity in terms of growth experiences, as shown in Table 2: focusing only on households who owned cattle, growth episodes are almost as likely as decreases or stagnation in herd size.

In 2004 we also collected new data on households' subjective expectations of herd dynamics. The use of elicited expectations to study decision-making has now been applied extensively for testing economic hypotheses in both 
Table 2: PARIMA data: heterogeneity in growth, 2000-2003

\begin{tabular}{cccc}
\hline \hline Growth & no cattle & $\begin{array}{c}\text { herd below } \\
\text { threshold }\end{array}$ & $\begin{array}{c}\text { herd above } \\
\text { threshold }\end{array}$ \\
\hline negative & - & 47 & 11 \\
0 & 57 & 66 & 14 \\
positive & 9 & 128 & 25 \\
\hline $\mathrm{N}$ & 66 & 241 & 50 \\
\hline
\end{tabular}

developed and developing countries (for reviews, see Manski, 2004, Hurd, 2009, Delavande, 2014, Delavande, Gine, and McKenzie, 2011). That said, it is worth explaining in some detail how we elicited these data.

We started by randomly selecting four hypothetical initial herd sizes for each respondent, one from each of the intervals defined by the equilibria identified by Lybbert et al. (2004). ${ }^{4}$ Respondents were then asked to characterize their expectations of rainfall during the coming year, choosing between good, normal or bad. ${ }^{5} 6$ Because the data were collected well into the rainy season, these answers should not be interpreted as uninformed priors, that could

\footnotetext{
${ }^{4}$ The intervals are $[1,5),[5,15),[15,40)$ and $[40,60]$ tropical livestock units (TLU) where $1 \mathrm{TLU}=1$ cattle $=0.7$ camels $=10$ goats or sheep. The TLU measure allows aggregation across species on the basis of animals' average adult metabolic weight. Among the Boran we study, the overwhelming majority of TLU are held in the form of cattle.

${ }^{5}$ This sort of trinomial rainfall characterization is familiar to respondents, as it corresponds to published rainfall forecasts such as those disseminated by the regional Drought Monitoring Centre and government and nongovernmental organization extension officers. See the analysis in (Luseno et al., 2003, Lybbert et al., 2007), who previously studied pastoralists' rainfall expectations

${ }^{6}$ In this and several other African rangelands ecosystems, pasture biomass covaries strongly with rainfall. In recent years, the density of grazing livestock and wildlife has been insufficient to affect biomass sufficiently to alter herd dynamics, with stocking rates well below carrying capacity outside of a relatively small cluster of overgrazed areas around settlements (McPeak, Little, and Doss, 2011). While climate change or a significant increase in human population and stocking rates could change the relationship between herd sizes and range vegetation dynamics, at the current time both appear driven largely by variation in weather. So the rainfall states we study should suffice to capture the stochastic dynamics of interest.
} 
merely reflect differences in optimism. ${ }^{7}$ Respondents were also asked to assume a herd of standard composition for the region (in terms of age and sex of the animals). In one site, and in a second separate interview, we additionally asked respondents to consider what would happen to their herd (with an identical randomly allocated initial herd size), in the case of more extreme weather conditions, namely severe drought and a very good year. ${ }^{8}$

After thus framing the problem, we asked each respondent to define the maximum and the minimum herd size they would expect to have one year later if they themselves started the year with the randomly assigned initial herd size. These bounds provide a natural anchor for the next step, in which we asked respondents to distribute, on a board, 20 stones among herd sizes between the minimum and the maximum previously elicited, thereby describing their subjective herd size distribution one year ahead conditional on the randomly assigned initial herd size and the statement about rainfall. Finally, each respondent was asked if s/he had ever managed a herd approximately equal in size to the initial value provided as the random seed. The elicitation of the probability distribution function is an appropriate technique under these circumstances (Morgan and Henrion, 1990) and allows us to compute conditional distributions and their moments. In addition, and because hypothetical initial wealth was randomly assigned to the respondent, it eliminates the prospective endogeneity of initial herd size in determining the estimated herd dynamics (Heckman, 1991).

In total, we have 460 observations, collected among 115 respondents for rainfall conditions labeled as good/normal or bad. Of these, 19 do not include a herd size prediction, usually because respondents were unable to distribute

\footnotetext{
${ }^{7}$ The geographical concentration of pastoralists' expectations regarding rainfall further reinforces this interpretation: in two sites, over $90 \%$ of the respondents expected bad rainfall, while in the other two sites, expectations were equally divided between 'bad rainfall' and 'good rainfall'.

${ }^{8}$ In particular, we asked respondents to consider herd evolution "as if" in 1999, the last major drought, or "as if" in a very good year, which we asked them to define based on their own experience.
} 
the stones across the board, a problem that occurred mainly for bigger initial herd sizes, when the difference between the maximum and the minimum was sometimes quite large. Of the remaining 441 observations, the respondents had prior personal experience managing a herd of comparable size in 288 cases $(65.3 \%)$. In addition, we have 61 similar observations for very good and very bad years.

We finish this brief description of the data we use by presenting, in figure 1, the scatter plot and kernel regression relating expected herd size one year ahead and initial herd size, conditional on ever having had a herd with a similar size but unconditional on weather conditions. ${ }^{9}$ Several points emerge from comparing pastoralists' subjective expectations of one year-ahead herd dynamics (figure 1) with the dynamics revealed by Desta/Lybbert et al.'s herd history data (in particular, the dashed line in Lybbert et al. (2004, p. 771 , figure 4), which reflects one year ahead dynamics).

First, both these data and the prior studies exhibit multiple dynamic equilibria consistent with the notion of a poverty trap. Second, however, the equilibria identified by pastoralists appear to differ markedly from those apparent in herd history data, both with respect to their location and stability. Notably, herd accumulation occurs for a wider range of initial herd sizes, while herd losses seem a relatively marginal occurrence, contradicting detailed studies of this system (Coppock, 1994) and the dynamics suggested by herd history data.

These casual comparisons invite more disaggregated analysis. Our data on herders' subjective expectations of herd dynamics (Figure 1) represent only one-year-ahead expectations under necessarily limited variability in rainfall regimes. By contrast, the pattern exhibited in the actual herd history data used by Desta/Lybbert et al. are the result of a mixture of environmen-

\footnotetext{
${ }^{9}$ We estimate Nadaraya-Watson nonparametric regressions with the Epanechnikov kernel and bandwidth of 4.545. The value of bandwidth was selected using Silverman (1986) rule of thumb, as determined by the "bounds for Stata" package (Beresteanu and Manski, 2000).
} 


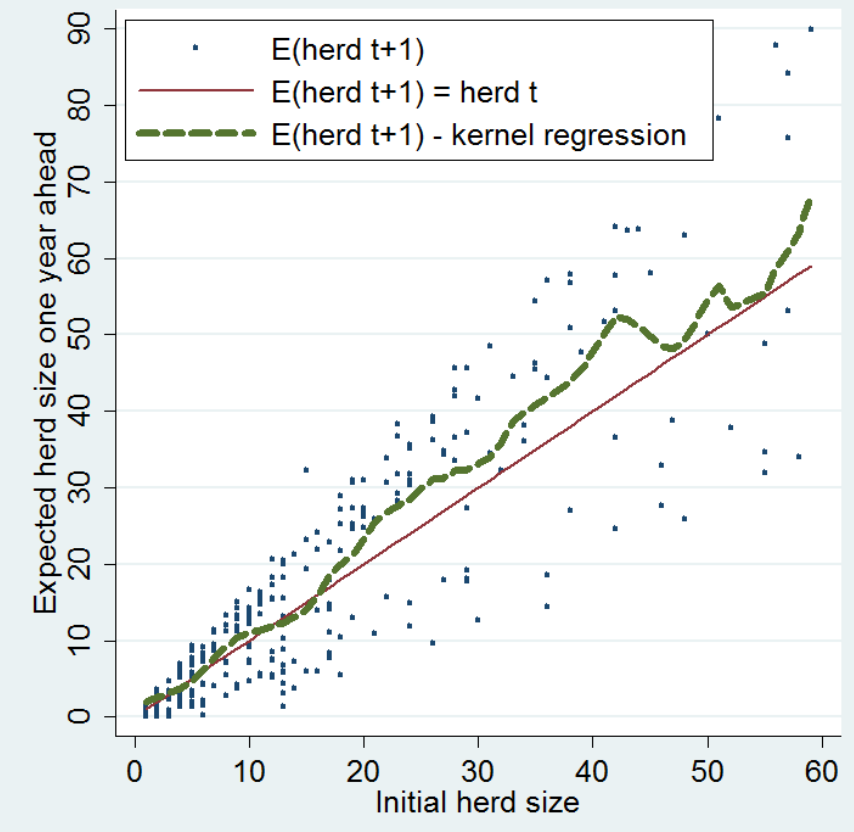

Figure 1: Unconditional subjective expected herd dynamics 
tal conditions over a period of 17 years. ${ }^{10}$ These differences are made clear in table 3, which summarizes the data on expected herd size one year ahead, conditional on state of nature and on having had a herd with a similar size, and its representation in figures 2 and 3, where we present the scatter plot and kernel regression relating expected herd size one year ahead and initial herd size for bad and normal/good years. ${ }^{11}$

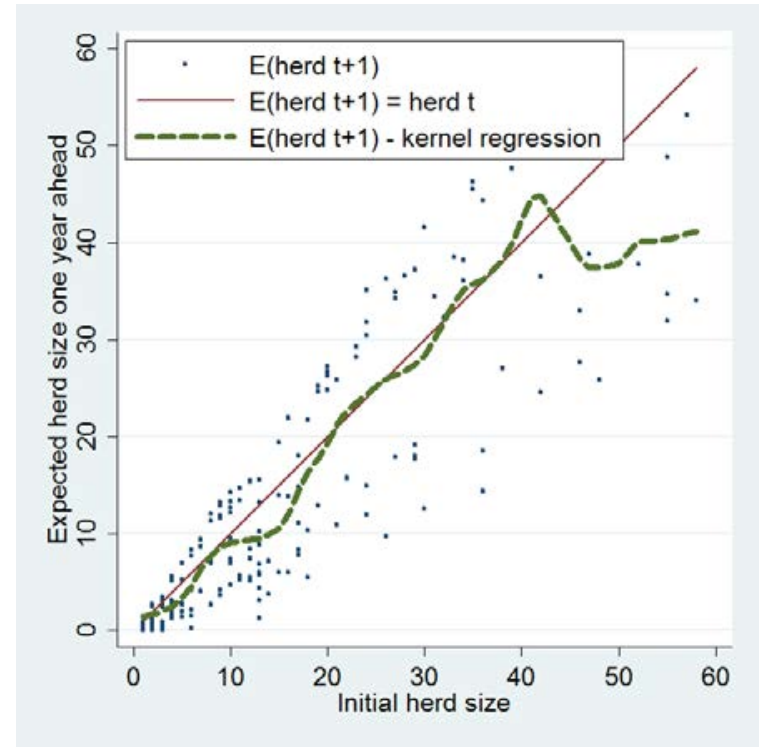

Figure 2: Expected herd dynamics under bad rainfall conditions

These plots, and the summary statistics in table 3 suggest two insights. First, the relation between expected and initial herd size is nonlinear only in

\footnotetext{
${ }^{10}$ For example, Kamara, Swallow, and Kirk (2004) identify three major droughts (1984/85, 1991/92 and 1995/96) and two periods of excessive rains (1980/81 and 1997/98) in this region over the period covered by the Desta/Lybbert et al. data. To these natural disasters, one may add the generalized ethnic clashes between the Boran and the Gabra in 1992, following the fall of the Derg regime. Barrett and Santos (2014) explore how changing rainfall distributions might impact observed herd dynamics.

${ }^{11}$ To conserve space, we omit figures reflecting the data and nonparametric regressions under extreme weather conditions, which show that during severe drought everyone expect to lose cattle.
} 


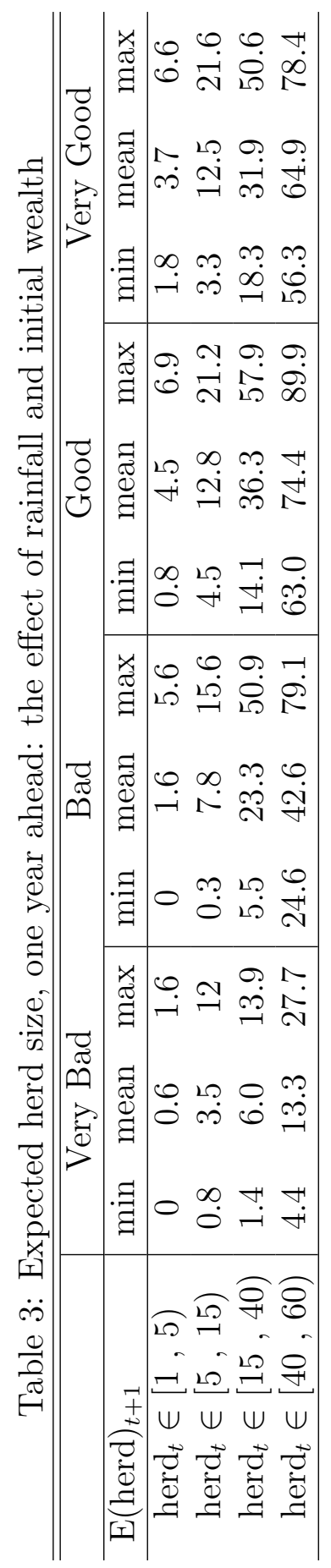






Figure 3: Expected herd dynamics under good or normal rainfall conditions

the case of bad rainfall conditions. Under good or normal climatic conditions (and perhaps unsurprisingly), almost all herders expect herd growth no matter the initial herd size. This disaggregation implies that adverse weather shocks drive the nonlinear dynamics revealed by the analysis of herd history data.

Second, the dispersion around the expected herd growth values is much bigger under conditions of bad rainfall than in a normal/good year. Herders exhibit far more heterogeneous beliefs about their ability to deal with adverse states of nature than with favorable ones. If, following Schultz (1975), one interprets this variation as at least partly reflecting pastoralist herding ability - assuming each pastoralist accurately perceives his or her own herd dynamics given his or her individual aptitude for herding - then perhaps "the ability to deal with disequilibria' plays a significant role in wealth dynamics. 


\section{Expected herd dynamics in a stochastic en- vironment}

In order to generate herders' subjective expectations of herd dynamics under a mixture of states of nature we need to integrate data on herd growth expectations conditional on rainfall (the elicited expectations data previously described) with historical rainfall data (in practice, monthly rainfall data for the four sites over the period 1991-2001). ${ }^{12}$ With this information we can then simulate herd evolution over longer periods than just one year ahead. Since we must predict out-of-sample in simulating herd evolution for large values of initial herd size, we estimate the parametric relation between initial and expected herd sizes (hereafter, herd ${ }_{1}$ and herd ${ }_{0}$, respectively) conditional on each of the four rainfall scenarios (drought (very bad), bad, normal/good , and very good). We estimate this relation with a respondent fixed effect specification, $\alpha_{i}$, taking advantage of having repeated observations, $r$, across different herd size intervals on each individual, $i$. We thus estimate

$$
\operatorname{herd}_{1 \text { ir }}=\mathrm{f}\left(\operatorname{herd}_{0 \text { ir }}\right)+\alpha_{\mathrm{i}}+\epsilon_{\text {ir }}
$$

where $\mathrm{f}\left(\operatorname{herd}_{0}\right.$ ir$)$ is a polynomial function of initial herd size. ${ }^{13}$ Table 4

\footnotetext{
${ }^{12}$ Average rainfall was $490 \mathrm{~mm} /$ year, with a standard deviation of $152 \mathrm{~mm} /$ year. Given the skewness and the kurtosis of this distribution, we cannot reject the null hypothesis that rainfall follows a normal distribution. The minimum annual rainfall over the period was registered in $1999(259 \mathrm{~mm})$ and the maximum in $1997(765 \mathrm{~mm})$. The probability of such events is 0.064 and 0.035 . Given these results, we assumed, for simulation purposes, a symmetric distribution, with a probability of extreme events (drought; or very good year) equal to 0.10. In a separate analysis (Barrett and Santos, 2014) we show that the results are relatively sensitive to changes in the rainfall distribution, reflecting the dependency of this system on rainfall and its vulnerability to climate change

${ }^{13}$ Besides the assumptions on the functional form of $\mathrm{f}(\bullet)$, we also assumed that $\epsilon_{i r} \sim \mathrm{N}\left(0, \sigma^{2}\right)$. Other specifications, that replace the fixed effect with other regressors that could affect subjective expectations, such as gender, age, experience and migrant status, were considered, but none of those variables proved statistically significant, so we omit these results. We omit higher order polynomial terms in the very good and good/normal year specifications because they added nothing given the good fit already achieved with a
} 
presents the estimates, which reflect the same results displayed visually in figures 2 and 3, and suggested in table 3: unambiguous, effectively linear expected growth under normal/good/very good rainfall conditions, and a nonlinear relation between herd $\mathrm{d}_{1}$ and herd $\mathrm{d}_{0}$ under conditions of poor rainfall and drought, and with considerable dispersion so that the precision of those estimates (as measured by the $\mathrm{R}^{2}$ ) is far less than under favorable rainfall regimes.

Table 4: Estimates of Expected Herd Dynamics Conditional on Rainfall

\begin{tabular}{l|cccc}
\hline \hline Variable & Very Good & Good & Bad & Very bad \\
\hline herd $_{0}$ & 1.293 & 1.477 & 0.528 & 0.246 \\
& $(0.000)$ & $(0.019)$ & $(0.224)$ & $(0.246)$ \\
herd ${ }_{0}^{2}$ & & & 0.026 & 0.009 \\
& & & $(0.010)$ & $(0.010)$ \\
herd ${ }_{0}^{3}$ & & & -0.00039 & -.00017 \\
& & & $(0.0001)$ & $(0.0001)$ \\
constant & 0.897 & 0.179 & 0.513 & -0.575 \\
& $(0.448)$ & $(0.416)$ & $(1.185)$ & $(1.083)$ \\
\hline $\mathrm{N}$ & 61 & 96 & 192 & 61 \\
$\mathrm{R}^{2}$ & 0.986 & 0.994 & 0.792 & 0.589 \\
\hline
\end{tabular}

Note: Values within parenthesis are robust standard errors

We then use these estimates to simulate the expected evolution of herd sizes ${ }^{14}$ Figure 4 presents the basic structure of the simulation procedure we used, while figure 5 presents the mean of 10-year ahead herd size for 500 replicates of this simulation with initial herd sizes between 1 and 60 .

simple linear specification with fixed effects.

${ }^{14}$ We calibrate these estimates to impose basic biological rules for livestock. More precisely, we do not allow for negative herds and impose that biological growth under good rainfall conditions is delayed in 2 years, i.e., enough for cows to reproduce in accordance with basic gestational patterns. We also constrain the predicted values for initial herd sizes above 52 (poor rainfall) and 45 (drought) to be linear, with a slope of 0.033 and 0.009 , respectively, preventing unbelievable predictions due to the parameter estimates at the boundaries of our sample. 


\begin{tabular}{l|c|l}
\hline $\mathrm{t}-1$ & $\mathrm{t}$ & $\mathrm{t}+1$ \\
\hline predict herd $_{t}$ & $\rightarrow$ rainfall draw & \\
$\left(\right.$ herd $_{0}$ given $)$ & $\downarrow$ & \\
& call $\mathrm{h}_{t+1}=\mathrm{f}\left(\mathrm{h}_{t} \mid\right.$ rainfall $)$ & \\
& $\downarrow$ & \\
& predict $\mathrm{h}_{t+1} \rightarrow$ & repeat as in $\mathrm{t}$ \\
\hline
\end{tabular}

Figure 4: Simulation procedure

The results are remarkably similar to the dynamics revealed by the herd history data (the solid line in Lybbert et al. (2004, p. 771, figure 4)), both in the general shape of the curve and in the location of the different equilibria. This strongly suggests that the mismatch observed earlier between the one year ahead transitions predicted by the two data sets (figure 1 and the dashed line in Lybbert et al. (2004, p. 771, figure 4)) arose because of differences in the underlying distribution of the states of nature; once we account for historical rainfall patterns and simulate the longer-term herd dynamics, it appears that Boran pastoralists' subjective expectations reflect a remarkably accurate understanding of the nature of how their herds have evolved over the past generation. In particular, they expect that someone with a herd below approximately 15 cattle will eventually lose almost all of his wealth, collapsing into a destitute equilibrium with just 1 cow.

Can we be sure that multiple equilibria exist? Given the small sample size, the answer is "no"; the lower confidence band crosses the equilibrium line only once, from above, at the lower level equilibrium (1 animal). But as we show below, this merely reflects our current assumption that all herders follow the same growth path. When we disaggregate by herder ability, the precision of our estimates improves significantly.

Concentrating on our average estimates, do these nonlinearities lead to a poverty trap? The answer depends, in part, on what one means by a "poverty trap". In Table 5 we quantify the probability of moving between 




Figure 5: Simulated expected herd dynamics

equilibria over a 10 year period given the stochastic nature of these shocks. There is a positive probability that a herder starting with a herd between 1 and 4 cattle will, 10 years later, have grown his herd. Indeed, there is even a very small $(<1$ percent) probability that he finishes above the accumulation threshold. Hence, under the strictest interpretation of a poverty trap - that initial conditions totally determine future wealth and the system is nonergodic, thus the probability of growing to a higher equilibrium is zero finds no support in our data. However, the probability of moving out of poverty is quite low (less than 12\%), suggesting that, in this context, the idea of a poverty trap is most usefully conceptualized as a high probability that agents will remain at lower levels of welfare, a weaker but perhaps more 
Table 5: Estimated herd size ten year transition matrix

\begin{tabular}{l|cccc}
\hline \hline $\begin{array}{l}\text { herd }_{t+10} \\
\text { herd }_{t}\end{array}$ & $0-4$ & $5-14$ & $15-39$ & $>40$ \\
\hline $1-4$ & 0.879 & 0.113 & 0.009 & 0.000 \\
$5-14$ & 0.575 & 0.262 & 0.133 & 0.030 \\
$15-39$ & 0.204 & 0.280 & 0.255 & 0.261 \\
$>40$ & 0.136 & 0.230 & 0.291 & 0.342 \\
\hline \hline
\end{tabular}

realistic interpretation of the concept in stochastic environments (Azariadis and Stachurski, 2005).

Summarizing the results so far, we find that Boran pastoralists accurately perceive long-term herd dynamics characterized by multiple wealth equilibria consistent with the notion of a poverty trap: shocks almost totally prevent wealth accumulation that would allow herders at a low initial wealth level from escaping poverty. However, these dynamics seem entirely the result of an asymmetry in growth rates under different rainfall conditions. Growth is universally expected in good years while S-shaped dynamics seem to result from wealth-differentiated capacity to deal with bad rainfall conditions. ${ }^{15}$

Our data also show that, even in bad years, not all herders expect their herds to shrink. The considerable dispersion of beliefs about herd dynamics under adverse states of nature suggests that herder-specific characteristics, which we summarize as ability, may likewise play a central role in conditioning wealth dynamics among these Ethiopian herders. The next section investigates this hypothesis.

\footnotetext{
${ }^{15}$ This could explain why, for example, Mogues (2011) studying livestock accumulation in other regions of Ethiopia in the period 2000-03, with no major shocks in between, does not find evidence of such nonlinearities, and why Barrett et al. (2006) find evidence of an S-shaped curve for asset dynamics in the northern Kenya PARIMA sample, which included a major drought ending in 2001.
} 


\section{Ability and expected herd dynamics}

Herding in semi-arid environments is a difficult livelihood. One must know how to treat livestock diseases and injuries, protect cattle against predators, manage their nutrition, navigate to distant grazing and watering sites, assist in difficult calving episodes, etc. Not everyone learns and practices these diverse skills equally well. One would naturally expect herders with greater animal husbandry skills to enjoy faster herd growth and to be less subject to adverse shocks to herd size than less skilled herders. Put differently, the herd dynamics explored in the historical data and in the previous section may ignore salient differences in herder ability.

We explore the impact of differences in herding ability upon herd dynamics by using the PARIMA panel data on pastoralist households, described in section 2, to estimate herder ability using stochastic parametric frontier estimation methods for panel data (Kumbhakar and Lovell, 2000). More precisely, we estimate the herd growth frontier that explains herder $i$ 's herd size at the beginning of period $t, h_{i t}$, conditional on a vector of household attributes, $X_{i t-1}$, and herd size at the beginning of the prior period using a composed error term that includes a symmetric random component reflecting standard sampling and measurement error, $\psi$, and a one-sided term reflecting observation-specific but time-invariant inefficiency, $\phi_{i} \geq 0$, which we assume follows a truncated normal distribution, $N^{+}\left(\mu, \sigma^{2}\right)$ :

$$
\mathrm{h}_{\mathrm{it}}=\mathrm{f}\left(\mathrm{h}_{\mathrm{it}-1}\right)+\beta \mathrm{X}_{\mathrm{it}-1}-\phi_{\mathrm{i}}+\psi_{\mathrm{it}}
$$

We use an exogenous switching regressions specification for $f\left(h_{i t-1}\right)$ so as to incorporate the possibility of two different growth paths, depending on whether the herder is above or below the 15 cattle threshold identified by Lybbert et al. (2004).

Since these households were surveyed repeatedly from 2000-2003, we can take advantage of multiple observations for each herder to compute consistent 
herder-specific mean efficiency measures, i.e., each pastoralist's proximity to the herd frontier. The inefficiency parameter $\phi_{i}$ captures any time-invariant and period-average time-varying - unobservables associated with systematic deviation from the herd growth frontier. This parameter can clearly capture factors beyond the herder's period-average unobserved ability/skill, such as location-specific unobservables. But $\phi_{i}$ is almost surely strongly correlated with skill. Moreover, it is an open question whether it matters for targeting and programming if the features that cause systematic underperformance are intrinsic, immutable individual skill or community-level or slow-changing individual characteristics. The key is that there exist distinct groups of households who routinely out-perform or under-perform their neighbors, however we understand the structural genesis of those relative performance differences.

The interpretation of these estimates as proxies for ability can still be contested on at least two grounds. First, the lagged values of herd size are clearly related to lagged (and current) ability, hence our estimates of inefficiency are likely inconsistent. This would matter if we were interested in cardinal measures of inefficiency. But we focus only on the ordinal measures, grouping households into low and high ability cohorts. So long as the correlation between lagged wealth and ability does not affect the ordering of each observation within the inefficiency distribution, the possible bias in point estimates will be of no consequence for present purposes.

Second, we estimate inefficiency by imposing a specific functional form, a specific distribution for the inefficiency parameter, and a specific accumulation threshold that, from the existing literature (in particular Lybbert et al. (2004)), seems valid for the average herder in this setting. These assumptions can introduce misspecification error that may be easily conflated with inefficiency (Sherlund, Barrett, and Adesina, 2002). As with the prior concern about inconsistent parameter estimates, our reliance purely on the ordering of the estimates sharply limits the relevance of such concerns. Nonetheless, 
an alternative approach is to use more flexible, nonparametric efficiency estimation methods, in particular Data Envelopment Analysis, that can easily allow for variable returns to scale without imposing a specific functional or distributional forms (see Coelli et al., 2005). Our analysis is robust to this alternative way of estimating inefficiency (results available from the lead author by request), so we maintain that the ordinal inefficiency estimates we estimate provide a reasonable proxy for relative herder ability/skill and thus serve present purposes well. ${ }^{16}$

Table 6 presents estimates of the herd growth frontier based on 2000-1, 2001-2 and 2002-3 annual observations for the 113 households for which we have complete data on each of the covariates. ${ }^{17}$ The results indicate statistically significant $(\mathrm{p}$-value $=0.053$ ) differences in the asset dynamics above and below the threshold, with expected herd growth (collapse) above (below) the threshold. The estimated frontier is piecewise quadratic in herd $d_{t}-h e r d_{t-1}$ space, as higher order polynomial terms of lagged herd size have no statistically significant effect. ${ }^{18}$ Household labor and land endowments have no effect at the margin on expected herd growth, signaling that these are not limiting in this environment for most households. Male-headed households enjoy significantly higher herd growth rates, which may partly capture household composition effects (with male-headed households having more men avail-

\footnotetext{
${ }^{16}$ The DEA estimates were obtained using the -dea- command in Stata (Ji and Lee, 2010). The results are available from the lead author by request.

${ }^{17}$ Because one of the households is the successor of an initial household, we only have data for the last two years. Hence, we're using an unbalanced panel, with 338 observations.

${ }^{18}$ Table 1 defines these variables and presents the descriptive statistics. We also estimated this regression using cubic and quartic terms, but none of the higher-order polynomials were statistically significantly different from zero and one could not reject the null hypothesis that the higher-order terms jointly have no effect on next period's herd size, once one allows for the threshold effect. The variable "no cattle at $t-1$ " is included to control for the fact that herd growth is different when one has no cattle - growth can then only occur through purchases or gifts, both of which are very infrequent (Lybbert et al., 2004) - than when one has a positive herd size. Although the point estimate on this variable is not statistically significantly different from zero, when we do not control for this effect, the estimated coefficients on lagged herd size and its various interactions become far more imprecise.
} 
able to herd, especially on treks away from base camp lasting days or weeks, holding labor availability constant). There exist statistically significant, albeit diminishing, marginal returns to herding experience. And there are marginally significant fixed effects associated with location and year (in particular, for 2001-2, the year of recovery after the severe 1999-2000 drought), the latter result reinforcing our earlier finding about state-dependent growth. The estimated distribution of the inefficiency estimates (with cattle as the units of measure) is presented in figure $6,{ }^{19}$ allowing a visual analysis of the within-sample variation.

Table 6: Stochastic parametric herd growth frontier estimates

\begin{tabular}{l|c|c|c}
\hline \hline variable & coefficient & std. err. & p-value \\
\hline herd size at t-1*above threshold & 1.022 & 0.093 & 0.000 \\
herd size at t-1 squared ${ }^{*}$ above threshold & 0.000 & 0.001 & 0.689 \\
herd size at t- ${ }^{*}$ below threshold & 0.890 & 0.307 & 0.004 \\
herd size at t-1 squared ${ }^{*}$ below threshold & -0.009 & 0.022 & 0.681 \\
no cattle at t-1 & -1.126 & 1.245 & 0.366 \\
labor * above threshold & -0.089 & 0.174 & 0.611 \\
labor * below threshold & 0.099 & 0.125 & 0.427 \\
land & 0.022 & 0.152 & 0.885 \\
sex & 1.333 & 0.702 & 0.057 \\
experience & 0.137 & 0.071 & 0.052 \\
experience squared & -0.002 & 0.001 & 0.174 \\
migrant & -0.605 & 0.998 & 0.544 \\
2000-01 & -0.740 & 0.531 & 0.164 \\
2001-02 & 1.553 & 0.525 & 0.003 \\
Dida Hara & 1.870 & 1.110 & 0.092 \\
Qorate & 0.026 & 1.229 & 0.983 \\
Wachille & 0.827 & 1.131 & 0.465 \\
constant & 13.012 & 195.554 & 0.947 \\
$\mu$ & 14.671 & 195.551 & 0.940 \\
\hline \hline $\mathrm{N}$ & & 338 & \\
$\mathrm{R}^{2}$ & & 0.230 & \\
\hline
\end{tabular}

${ }^{19}$ Estimated using the Epanechnikov kernel, with a bandwidth of 0.24697. 




Figure 6: Empirical density function of herd growth inefficiency estimates

Using the predicted value of each herder's estimated inefficiency, we then divide our sample into two sub-samples: lower ability (those in the 4th quartile of the inefficiency estimates, with $\phi_{i}>15.38$ ) and a complementary category of higher ability herders. The observations are concentrated around just a few points ranges of inefficiency estimates, suggesting that there may be little value to further subdivision of the sample. ${ }^{20}$ For each of these two classes we re-estimate equation 1, obtaining estimates of the parametric models that relate expected and initial herd size for each sub-sample, after which we performed the same simulation as above. ${ }^{21}$ Figure 7 shows the

\footnotetext{
${ }^{20} \mathrm{We}$ also experimented with splitting the higher ability herders into two categories, those of highest ability (the 1st quartile of the inefficiency distribution) and a residual medium ability class (the 2 nd and 3rd quartiles). The qualitative results are similar, so we present the simpler approach here. Results of the most disaggregated analysis are available from the lead author by request.

${ }^{21}$ These 8 parametric models (4 states of nature x 2 ability classes) are qualitatively similar to the ones presented in Table 4 . To conserve space, we omit them here but make them available from the lead author by request.
} 


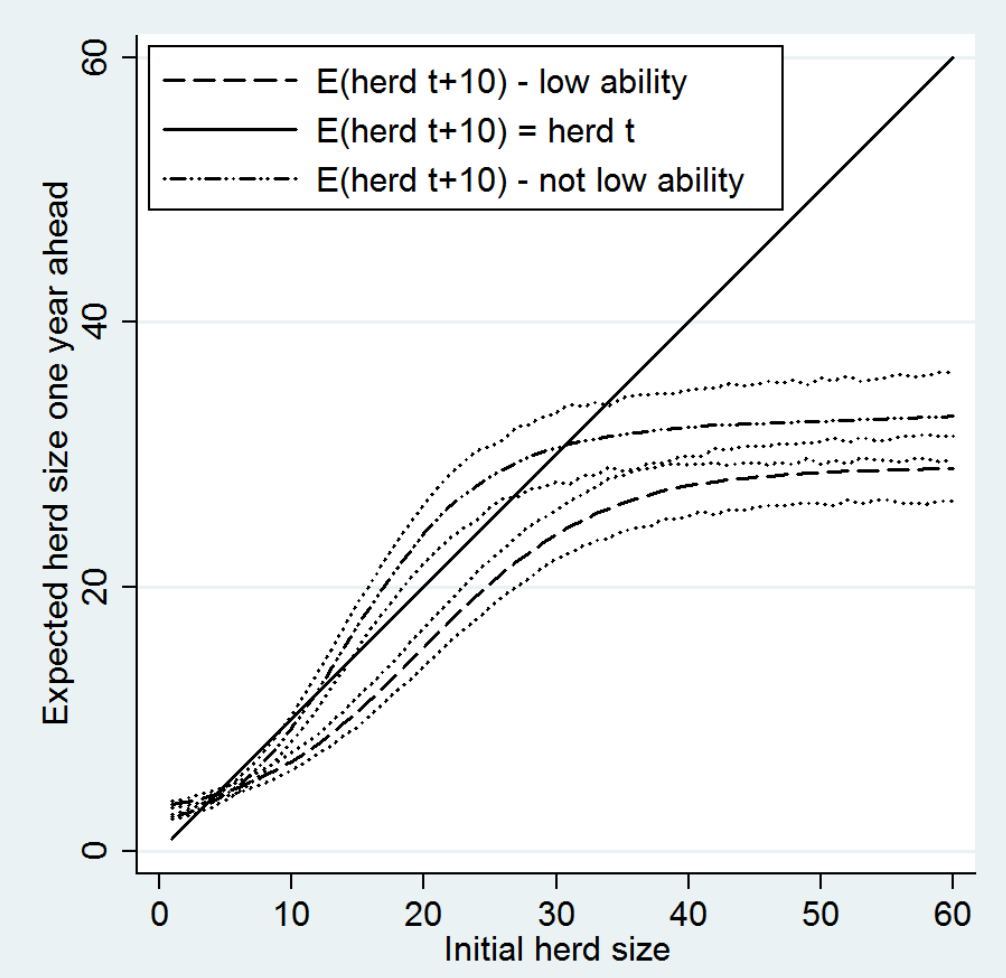

Figure 7: Simulated expected herd dynamics - the effect of ability

nonparametric conditional expectation function (and 95 percent confidence intervals) of 10-year-ahead herd size obtained for 500 replicates with initial herd sizes between 1 and 60 cattle for each ability class. The results are easily summarized.

Although those in the lowest ability quartile exhibit S-shaped expected herd dynamics, these lie everywhere beneath the dynamic equilibrium line (the solid $45^{\circ}$ line in figure 7 ). Thus, low ability herders are expected to converge towards the low level dynamic asset equilibrium of 1-2 head of cattle over time. Recall that all herders expect to grow their herds during good and normal rainfall years. So this expected long-run herd size collapse arises entirely from low ability herders difficulty in managing and recovering 
from adverse weather shocks.

Higher ability herders likewise exhibit S-shaped expected herd dynamics. However, they face multiple dynamic equilibria, with a threshold (i.e., unstable dynamic equilibrium) at 11-17 cattle, similar to the threshold estimated by Lybbert et al. (2004) from the herd history data. Notice also that, when we allow for different growth paths conditional on ability, we get much more precise estimates of the herd dynamics within this system. In particular, both confidence bands for the higher ability herders cross the dynamic equilibrium line in three points, two of which represent stable dynamic equilibria, at 1-2 and 29-35 cattle, respectively. The implication, reflected in figure 7, is that S-shaped herd dynamics characteristic of a multiple equilibrium poverty trap are not followed by all herders. Low ability herders face a unique dynamic equilibrium at lower levels of welfare, giving rise to a different sort of poverty trap than that faced by herders with higher ability, who expect to accumulate wealth so long as they maintain an herd size above the 12-17 cattle threshold. These results clearly raise important practical questions with respect to any asset redistribution or transfer policy, as ability is not easily and quickly identified in conventional survey methods, at least not by outsiders such as the governmental and nongovernmental agencies that typically provide transfers and public safety net programs.

\section{Expected growth and inequality among the Boran}

We now apply this simulation approach to analyze the expected evolution of wealth and inequality in our sample of respondents. We use the same approach as above on the subsample of 97 households that owned cattle in 2003. ${ }^{22}$ Table 7 presents the results for expected average herd size 10

\footnotetext{
${ }^{22}$ From our sample of 120 respondents, 5 were not interviewed in 2003 and 18 had no cattle. Given that we did not elicit the expectations about herd evolution for stockless
} 
years ahead and for expected inequality, based on 500 runs of our simulation procedure, first when we disregard the effect of herder ability (column b), then when we incorporate it (column c).

Table 7: Expected evolution of wealth and inequality among the Boran

\begin{tabular}{|c|c|c|c|}
\hline & $\begin{array}{l}t=0 \\
\text { (a) }\end{array}$ & $\begin{array}{c}\mathrm{t}=10 \\
\text { (disregarding ability) } \\
\text { (b) }\end{array}$ & $\begin{array}{c}\mathrm{t}=10 \\
\text { (considering ability) } \\
(\mathrm{c})\end{array}$ \\
\hline Average herd size & $\begin{array}{c}12.76 \\
(1.49)\end{array}$ & $\begin{array}{c}9.61 \\
(3.34)\end{array}$ & $\begin{array}{l}15.85 \\
(8.89)\end{array}$ \\
\hline Gini coefficient on herd size & $\begin{array}{c}0.46 \\
(0.05)\end{array}$ & $\begin{array}{c}0.66 \\
(0.04)\end{array}$ & $\begin{array}{c}0.71 \\
(0.07)\end{array}$ \\
\hline
\end{tabular}

The results are simple to interpret. When we take into consideration the role individual heterogeneity plays in shaping wealth dynamics (column c), we should expect both an increase in average herd size and a large increase in inequality over time, as low ability herders collapse into destitution and higher ability herders steadily grow their livestock holdings. If we simulate the evolution of the wealth of this population with a simpler approach that neglects such differences (column b), then we still expect an increase in inequality (although somewhat smaller), but with a decrease in average wealth.

\section{The policy challenge: targeting with un- known dynamics}

The possibility that multiple mechanisms underpin wealth dynamics poses a challenge for policymakers. To illustrate how an understanding of wealth dynamics might affect the design and performance of an intervention, we herders and that, to the best of our knowledge, there are no reliable estimates of the rate of re-entry into pastoralism for herders who lost all their cattle, we dropped them from the simulation. Among those with no cattle in 2003, 5 households (or 27\%) were classified as of being of low ability. 
explore the effectiveness of herd restocking in this system, as this is perhaps the most common form of post-drought assistance provided to pastoralists by donors and governments in the region.

We simulate the effect of three different scenarios under the maintained assumption that growth does depend on ability (as represented in figure 7) and using a constant budget. In Scenario 1, all herds below five cattle (a customary, Boran-defined poverty line) are given animals to boost their herd to five head, irrespective of the recipient herder's ability. This reflects the dominant current paradigm of progressive transfers to the poorest. In our simulations, in aggregate that rule leads to a transfer of 36 cattle to 17 beneficiaries in our 2003 sample of 97 households. Those 36 cattle become the fixed "budget" that we maintain in the next two scenarios. In Scenario 2, we simulate the effects of a transfer targeted so as to maximize the number of "viable" herders, that is, those that have a herd that is larger than the estimated minimum accumulation threshold of 11 cattle. Although we assume that growth depends on ability, we also assume that there exists no effective mechanism to elicit herder ability; so transfers are conditioned solely on observable herd sizes. Then in Scenario 3, we assume one can accurately identify herder by ability group and, as with Scenario 2, again target transfers so as to maximize asset growth. Scenario 3 involves transfers to 16 higher ability herders, with limited overlap in identity with the 17 recipients under scenario 1. The main difference between these scenarios is evident in Figure 8, where we draw the expected herd growth associated with the transfer of one cattle, conditional on herder ability.

Given expected herd dynamics over the decade following the hypothesized transfer, the transfer is expected to generate herd growth, net of the one cattle transfer (i.e., expected gains $>1$ ), only for higher ability recipients with $e x$ ante herd size between 9 and 22 head. Herders of low ability or, if of higher ability, with the smallest (or largest) herds are expected to lose some of their post-transfer herd over the ensuing decade, signaling negative medium-to- 


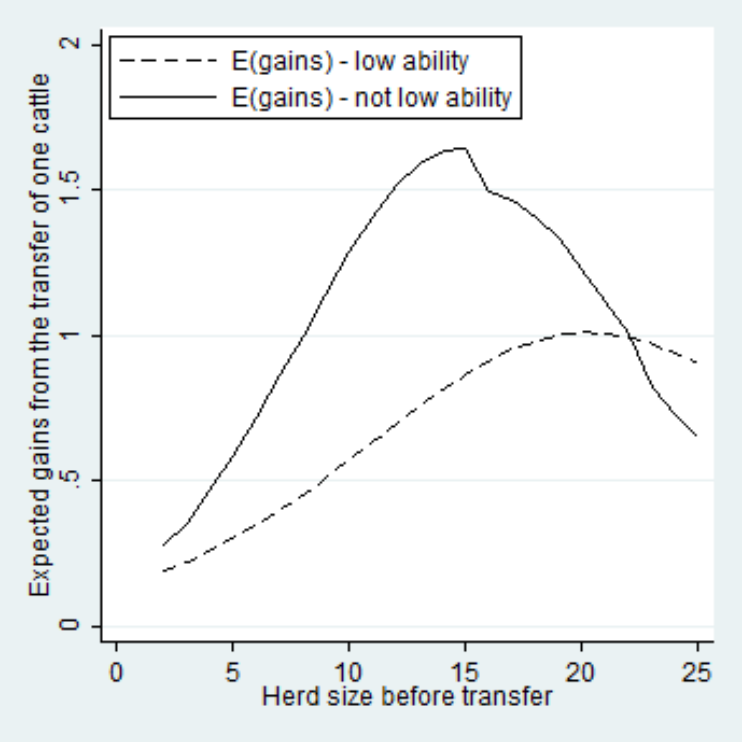

Figure 8: Expected gains from the transfer of one cattle

long term growth returns on livestock transfers to the poorest (or wealthiest) herders of higher ability. The expected herd gain is maximized for a transfer to a higher ability herder with an ex ante herd size of 15 cattle, a significantly larger herd than is typical of restocking program participants, since such interventions are typically targeted following some poverty reduction criteria, like Scenario 1.

Table 8 presents the results of a comparison among these three different scenarios for targeting herd restocking transfers which reflect both this discussion and, implicitly, the distribution of low and high ability types as function of pre-transfer wealth, as represented in figure 9

As one would expect based on the growth dynamics of this system, restocking targeted to lower wealth households (specifically, those fewer than five cattle) fails to promote growth among the poor. After 10 years, beneficiaries enjoy an expected gain of 0.86 cattle, but from an average transfer of 2.12 cattle. This implies a $-4.4 \%$ compound annual return on investment in 


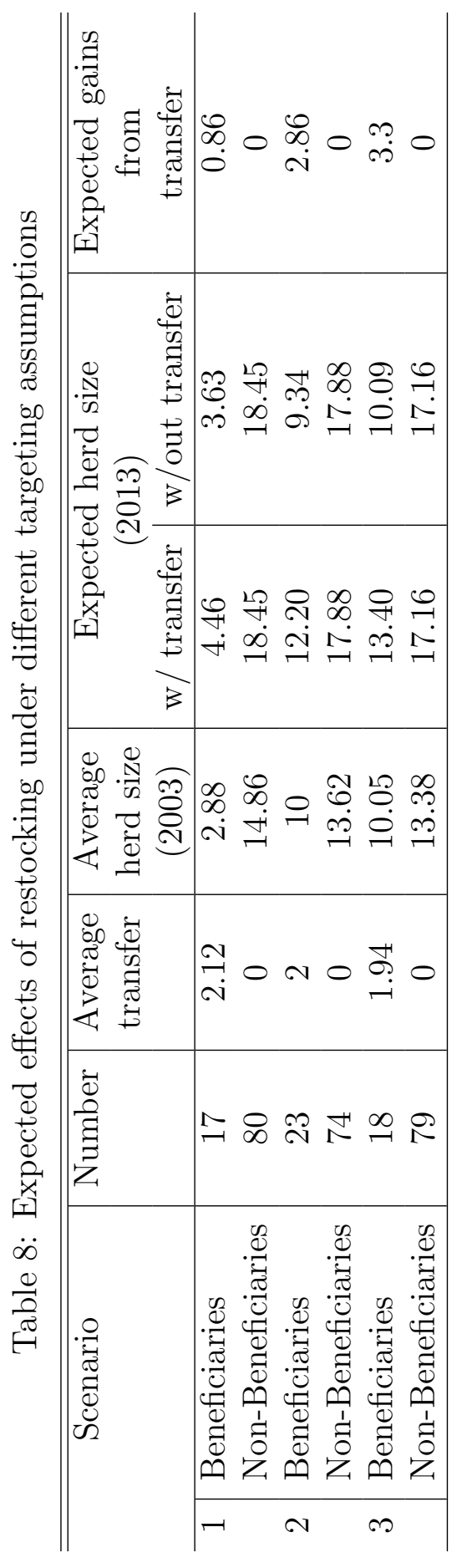




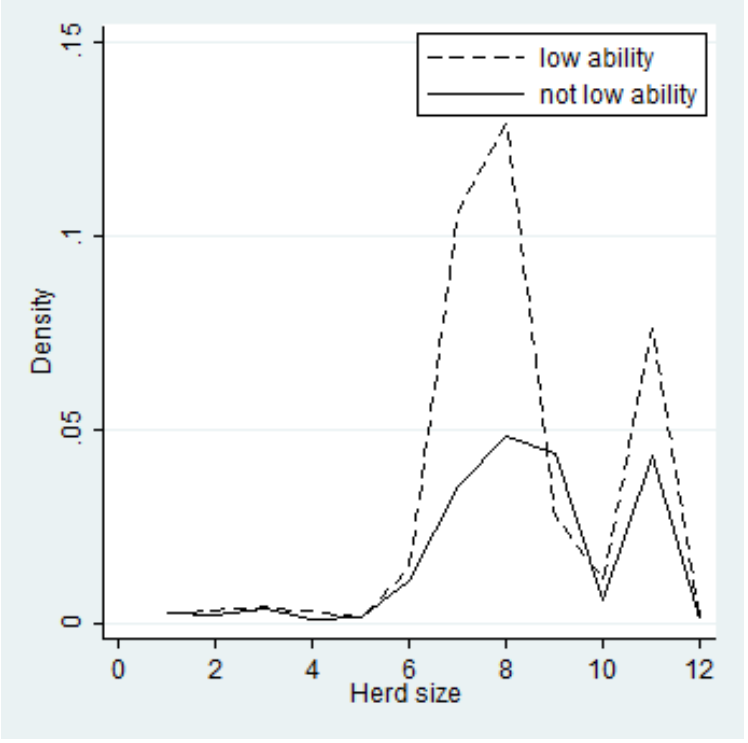

Figure 9: Distribution of high and low ability types as a function of initial wealth

transfer resources, reflecting expected herd losses below the critical herd size threshold. The growth-promoting impacts of herd restocking become more satisfactory in the other two scenarios, that target those who can reach the herd accumulation threshold through transfers rather than the ex ante poorest households. Under scenario 2, the average net returns to this policy after 10 years are $43 \%$ (3.6\% annually). These returns significantly increase to $70 \%$ ( $5.4 \%$ annually), under scenario 3 , showing that the payoff to the design of a reliable mechanism for identifying herding ability is potentially considerable, given that ability seems to matter a great deal to wealth dynamics in this system. But targeting the accumulation threshold is the main factor that drives achieving a positive long-run rate of return on transfer resources.

This payoff naturally depends on the distribution of ability types. As shown in figure 9 there is, in this system at least, a correlation between ex ante wealth and ability that reflects the joint operation of the dynamics described 
in this paper - with low ability types expected to fall into and remain in poverty regardless of initial wealth - and the insufficiency of informal insurance, particularly among the poor (Santos and Barrett, 2011). Roughly half of the herders with less than five cattle are classified as low ability (which, recall, we defined as being in the lower quartile of the distribution of our estimates of technical efficiency). The frequency of low ability herders then diminishes with wealth: $22 \%$ of the beneficiaries of transfers under Scenario 2 (with herds between 9-11 cattle) are classified as of low ability, and only little more than $10 \%$ of the herders with wealth above the accumulation threshold are classified as such. The challenge intrinsic to restocking projects targeted at those with small herds is that it implicitly favors those with the least ability to manage the livestock they receive. This finding lends support to recent policy initiatives in the east African drylands that focus more on cash transfers than livestock transfers to support the poorest community members.

\section{Conclusions}

Using unique data on subjective herd growth expectations conditional on expected rainfall, we find that southern Ethiopian pastoralists appear to understand the nonstationary herd dynamics that long-term herd history data suggest characterize their system, corroborating Lybbert et al. (2004) and related results using different data and methods. Moreover, pastoralists' responses reveals that multiple dynamic equilibria arise purely due to adverse shocks associated with low rainfall years and only among pastoralists of higher herding ability. Lower ability herders appear to converge towards a unique, low-level equilibrium herd size. When adverse weather events strike, they lose livestock and, in expectation, cannot recover quickly enough before the next drought hits. Thus, the data suggest that even among a seemingly homogeneous population in an ethnically uniform region offering effectively only one livelihood option - livestock herding - there exist complex wealth 
dynamics characterized by distinct convergence clubs defined by individual ability, with multiple dynamic equilibria existing for only a subset of those clubs and a unique stable dynamic equilibrium for the other clubs.

These findings carry two very general policy implications. First, the need for interventions to lift people out of - or to prevent their collapse into poverty traps, seems to depend on the nature of the adverse shocks, in particular whether their severity and frequency is such that growth under favorable states of nature is often and sharply reversed, making accumulation below a critical threshold unlikely (albeit not impossible). Risk mitigation or transfer methods to limit the frequency or magnitude of shocks may be as or more valuable than transfers to facilitate growth among the poorest. Second, the appropriate design and targeting of social protection in this stochastic environment depend very much on individual characteristics, perhaps including difficult-to-observe characteristics such as ability. Identifying ability may be operationally difficult, but failure to take such characteristics into account may lead to ill-conceived efforts and wasted scarce resources. 


\section{References}

Azariadis, C., and J. Stachurski. 2005. "Poverty Traps." In P. Aghion and S. Durlauf, eds. Handbook of Economic Growth. Amsterdam: Elsevier.

Barrett, C., and M. Carter. 2013. "The economics of poverty traps and persistent poverty: empirical and policy implications." Journal of Development Studies 49:976-990.

Barrett, C., T. Garg, and L. McBride. forthcoming. "Well-Being Dynamics and Poverty Traps." Annual Review of Resource Economics 8.

Barrett, C., and P. Santos. 2014. "The impact of changing rainfall variability on resource-dependent wealth dynamics." Ecological Economics 105:48-54.

Barrett, C.B., G. Gebru, J.G. McPeak, A.G. Mude, J. Vanderpluye-Orgle, and A.T. Yirbecho. 2004. "Codebook for data collected under the improving pastoral risk management on East Africa rangelands (PARIMA) project." Unpublished, Cornell University.

Barrett, C.B., P.P. Marenya, J. Mcpeak, B. Minten, F. Murithi, W. OluochKosura, F. Place, J.C. Randrianarisoa, J. Rasambainarivo, and J. Wangila. 2006. "Welfare dynamics in rural Kenya and Madagascar." The Journal of Development Studies 42:248-277.

Baumol, W.J. 1986. "Productivity growth, convergence and welfare: what the long run data show." American Economic Review 76:1072-85.

Beresteanu, A., and C.F. Manski. 2000. "Bounds for Stata: draft version 1.0." Unpublished, Northwestern University.

Bowles, S., S. Durlauf, and K. Hoff. 2006. Poverty traps. Princeton, NJ: Princeton University Press. 
Canova, F. 2004. "Testing for convergence clubs in income per capita: a predictive density approach." International Economic Review 45:49-77.

Card, D. 1995. "Earnings, schooling and ability revisited." Research in Labor Economics 1:30-67.

Carter, M. 1997. "Environment, technology and the social articulation of risk in West African agriculture." Economic Development and Cultural Change 45:151-163.

Carter, M., and C. Barrett. 2006. "The economics of poverty traps and persistent poverty: An asset-based approach." The Journal of Development Studies 42:178-199.

Carter, M.R. 1998. "On the economics of realizing and sustaining an efficient redistribution of productive assets." In E. O. Wright, ed. Recasting Egalitarianism: New rules for accountability and equity in markets, communities and states. London: Verso.

Coelli, T.J., D.S.P. Rao, C.J. O’Donnell, and G.E. Battese. 2005. An Introduction to Efficiency and Productivity Analysis. New York: Springer.

Coppock, D.L. 1994. The Borana plateau of southern Ethiopia: synthesis of pastoral research, development and change, 1980-91. No. 5 in International Livestock Centre for Africa Systems Study, Addis Ababa: ILCA.

Delavande, A. 2014. "Probabilistic expectations in developing countries." Annual Review of Economics 6:1-20.

Delavande, A., X. Gine, and D. McKenzie. 2011. "Measuring subjective expectations in developing countries: a critical review and new evidence." Journal of Development Economics 94:151-163.

DeLong, J.B. 1988. "Productivity growth, convergence and welfare: comment." American Economic Review 78:1138-54. 
Dercon, S. 1998. "Wealth, risk and activity choice: cattle in Western Tanzania." Journal of Development Economics 55:1-42.

Desta, S. 1999. "Diversification of livestock assets for risk management in the Borana pastoral system of southern Ethiopia." PhD dissertation, Utah State University, Logan, UT.

Evans, D., and B. Jovanovic. 1989. "An estimated model of entrepreneurial choice under liquidity constraints." Journal of Political Economy, pp. 808827.

Heckman, J. 1991. "Identifying the Hand of the Past: Distinguishing State Dependence from Heterogeneity." American Economic Review 81:75-79.

Hurd, M.D. 2009. "Subjective probabilities in Household Surveys." Annual Review of Economics 1:543-562.

Ji, Y., and C. Lee. 2010. "Data Envelopment Analysis." The Stata Journal $10: 267-280$.

Kamara, A., B. Swallow, and M. Kirk. 2004. "Policies, interventions and institutional change in pastoral resource management in Borana, southern Ethiopia." Development Policy Review 22:381-403.

Kraay, A., and D. McKenzie. 2014. "Do poverty traps exist? Assessing the evidence." Journal of Economic Perspectives 28:127-148.

Kumbhakar, S., and C.A.K. Lovell. 2000. Stochastic Frontier Analysis. Cambridge: Cambridge University Press.

Luseno, W.K., J.G. McPeak, C.B. Barrett, G. Gebru, and P.D. Little. 2003. "The value of climate forecast information for pastoralists: evidence from Southern Ethiopia and Northern Kenya." World Development 31:1477-94. 
Lybbert, T., C.B. Barrett, S. Desta, and D.L. Coppock. 2004. "Stochastic wealth dynamics and risk management among a poor population." Economic Journal 114:750-777.

Lybbert, T., C.B. Barrett, J. McPeak, and W.K. Luseno. 2007. "Bayesian herders: asymmetric updating of rainfall beliefs in response to external forecasts." World Development 35:480-497.

Manski, C.F. 2004. "Measuring expectations." Econometrica 72:1329-1376.

McPeak, J., P. Little, and C. Doss. 2011. Risk and social change in an African rural economy. London: Routledge.

Mogues, T. 2011. "Shocks and asset dynamics in Ethiopia." Economic Development and Cultural Change 60:91-120.

Morgan, M.G., and M. Henrion. 1990. Uncertainty. A guide to dealing with uncertainty in quantitative risk and policy analysis.. Cambridge: Cambridge University Press.

Rosenzweig, M., and H.P. Binswanger. 1993. "Wealth, weather risk and the composition and profitability of agricultural investments." Economic Journal 103:56-78.

Sachs, J.D. 2005. The end of poverty: economic possibilities for our times. New York: Penguin Press.

Santos, P., and C. Barrett. 2011. "Persistent poverty and informal credit." Journal of Development Economics 96:337-347.

Schultz, T.W. 1975. "The value of the ability to deal with disequilibria." Journal of Economic Literature 13:827-846.

Sherlund, S.M., C.B. Barrett, and A.A. Adesina. 2002. "Smallholder technical efficiency controlling for environmental production functions." Journal of Development Economics 69:85-101. 
Silverman, B. 1986. Density estimation for statistics and data analysis. London: Chapman \& Hall.

Toth, R. 2015. "Traps and Thresholds in Pastoralist Mobility." American Journal of Agricultural Economics 97:315-332.

United Nations Millenium Project. 2005. Investing in Development: A practical plan to achieve the Millenium Development Goals. New York: United Nations Development Program. 